\title{
"Construcción de Identidad en Jóvenes Infractores de Ley, una Mirada desde la Psicología Cultural"
}

\section{Identity Construction in Young Law Offenders from a Cultural Psychological Perspective}

\author{
Alba Zambrano Constanzo ${ }^{1}$ \\ Ricardo Pérez-Luco Arenas ${ }^{2}$
}

\begin{abstract}
Resumen
Este artículo aborda el proceso de construcción de identidad delictiva a través de un análisis teórico psicocultural que se nutre de distintas fuentes de la psicología contemporánea y otras disciplinas, derivando en el planteamiento de este proceso como determinante del surgimiento y consolidación de las conductas delictivas. Se argumenta que la infracción de ley configurada en un patrón de conducta recurrente, en el caso de un número importante de jóvenes, es la resultante de un proceso que tiene fuertes vinculaciones con un medio social desventajoso, que genera inseguridad, estrés, desesperanza y dificultades para resolver necesidades básicas materiales y psicológicas. Estos aspectos, entre otros, propician la construcción de una realidad social que ubica a determinados jóvenes al margen de los estándares socialmente aceptados. Finalmente, a la luz del análisis teórico, se proponen algunas estrategias generales para abordar esta dimensión de nuestra realidad.
\end{abstract}

Palabras claves: Psicología cultural, Jóvenes infractores de ley, construcción de identidad

\begin{abstract}
The present article approaches the process of construction of criminal identity through a psychocultural theoretical analysis that nourishes itself from different sources of contemporary psychology and other disciplines, deriving in the claim that this process becomes determinant of the sprouting and consolidation of criminal behavior. It is argued that, in the case of an important number of young people, the infraction of law turned into a pattern of recurrent behaviour as the result of a process that has a strong relationship with disadvantageous social environments, generating insecurity, stress, hopelessness and difficulties in the satisfaction of material and psychological basic needs. These issues, among others, induce the construction of a social reality that locates certain young people off the margins of socially accepted standards. Finally, in the light of this theoretical analysis, some general strategies are set forth in order to approach this dimension of our reality.
\end{abstract}

Keys words: Cultural psychology, transgression by the young, identity construction

1 Psicóloga, Universidad de la Frontera. Email: albaz@ufro.cl

2 Psicóloga, Universidad de la Frontera.Email: perezluc@ufro.cl 


\section{Introducción}

Estudios recientes del BID y otras organizaciones destacan que América Latina es hoy la segunda zona con más criminalidad en el mundo. Las opiniones centradas en la seguridad de los ciudadanos indican que un porcentaje importante de latinoamericanos, especialmente de las grandes ciudades, se sienten inseguros, señalando su percepción acerca del aumento de la delincuencia y la drogadicción (Kliksberg, 2001).

Distintas investigaciones constatan que parte importante de la delincuencia común es cometida por jóvenes; su tasa asciende progresivamente pasando a formar parte destacada de la crónica periodística de todos los días. Aquí cabe preguntarse acerca de ¿qué factores han incidido en que en nuestro continente, en general y en Chile en particular, este problema esté en franco crecimiento?

En la opinión pública es generalizada la convicción de que el delincuente actúa en forma intencional simplemente por maldad, por lo que merece ser castigado. Más aún se suele establecer una relación mecánica entre delincuencia, juventud y pobreza, por lo que medidas represivas y estigmatizadoras suelen contar con amplia popularidad.

En este artículo argumentaremos que la conducta delictiva que presentan algunos jóvenes que viven en condiciones de pobre$\mathrm{za}$, se enmarca en un proceso de inadaptación social de mayor alcance. Un proceso que afecta la construcción de identidad sobre la base de experiencias tempranas marcadas por la vivencia de estar "al margen de" y la consolidación de representaciones sociales que les ubica culturalmente en un espacio social con características particulares.

Así entendido el fenómeno de la delincuencia en jóvenes que viven condiciones de vidas desventajosas, demanda de actuaciones multinivel de mediano y largo plazo que contemplen el desafío y cuestionamiento de re- presentaciones sociales que están a la base de la construcción de identidad psicosocial y que han sido construidas en un marco cultural concreto, a la vez que, modificaciones objetivas en el entorno de vida. Proponemos en esta perspectiva un abordaje psicoeducativo de carácter comunitario.

\section{Una Aproximación Psicocultural}

Los jóvenes con compromiso delictivo que viven en condiciones de pobreza se adaptan o son afectados como personas, en su dimensión individual y social, por sus circunstancias de vida, sus historias familiares, su ubicación social; pero al mismo tiempo, ellos son agentes activos, contribuyentes a su realidad. Así, asumimos que la delincuencia es una construcción en la vida social, pero también en la biografía de quienes son denominados delincuentes. Como justificaremos en el desarrollo del artículo, los mecanismos que soportan esta construcción (aunque complejos) suponen un orden y funcionalidad que son necesarios de comprender, cuestionar y desafiar.

\section{Sistemas Sociales: Cultura y Discurso}

Como punto de partida muy general, para luego profundizar el tema de nuestro interés, es necesario preguntarnos ¿cómo las personas logramos reunirnos con cierto nivel de cohesión (aunque sea mínimo) a pesar de que seamos tan extraños? ¿Sobre qué construcción real o imaginaria se fundamentan las agrupaciones sociales?

Una primera aproximación permite señalar que las relaciones entre los seres humanos son invisibles, cada vez que entramos en relación con otro, comienza a actuar "el imaginario" compartido; un mundo simbólico que hace que los unos y los otros podamos comunicarnos y sentirnos parte de un todo. Esa coherencia y mundo simbólico compartido están cruzados por el discurso y la ideología. Sobre esa base se construye la subjetividad e identidad de las personas. 
$\mathrm{Al}$ analizar los diversos sistemas sociales podemos apreciar que se organizan de modo tal de asegurar su supervivencia, generando ordenamientos que les son propios. La existencia de un determinado orden en las acciones y relaciones entre sus miembros hace posible que el quehacer de cada uno no destruya u obstaculice el producto de la actividad de los demás. Este ordenamiento diverso e histórico da cuenta de una construcción que cumple funciones particulares para cada sistema social.

La ley es el marco regulador máximo de la convivencia de una determinada sociedad, pero también existen otros mecanismos normativos formales e informales que actúan en las diversas dimensiones de la convivencia humana (Martín-Baró, 1989). Lo que es claro es que los sistemas sociales y la normativa que los regulan, existen previo al individuo particular, pero éste es un actor activo en su construcción.

En esta perspectiva, autores como Berger y Luckman (1968), subrayan que la formación de un orden social determinado es de naturaleza humana. El ser humano en su proceso de adaptación vital es en buena medida un producto de un orden social, pero siguiendo a Martín-Baró (1989) añadimos que en su trayectoria vital el ser humano va produciendo, manteniendo o cambiando ese orden social.

La construcción de la normativa social y cultural según lo indican Rodríguez y Arnold (1991) se sustenta en el sentido compartido, que siendo una expresión cultural, se manifiesta a través del lenguaje en los discursos privados y públicos, pues éstos, en sus representaciones y articulaciones, revelan el orden simbólico. Este orden depende de la dinámica histórico-social y de los procesos de generación y consenso que se van articulando y desarticulando permanentemente a través de las contingencias temporales que acompañan la vida social y que se expresan tanto en la semántica de las culturas como en su estructura social.
Entenderemos por cultura al sistema de conocimientos que nos proporciona un modelo de realidad a través del cual damos sentido a nuestro comportamiento. Este sistema está formado por un conjunto de elementos interactivos fundamentales, generados y compartidos por el grupo de pertenencia (Aguirre, 2000).

La concepción simbólica de la cultura, destaca que los fenómenos culturales que hacen posible el sentido compartido, al que ya hemos aludido, obedece a fenómenos simbólicos; a la capacidad de los seres humanos para producir y reproducir diversas formas de símbolos y de acción simbólica (Thompson, 1998). Es necesario agregar a esta perspectiva, como lo señalan Glauben y cols. (1993), que el sentido compartido hace predecible lo impredecible, esto es, la constitución de sistemas sociales que posibilitan, por una parte el entendimiento cotidiano y por otra, el ejercicio desigual del poder.

Desde una perspectiva estructuralista John Thompson (1998), planea que la vida social es una cuestión de significado en donde los sujetos hacen uso del lenguaje en un contexto determinado, estructurado socialmente. Ello destaca la idea de la comunicación como un fenómeno que ocurre mediado por relaciones de poder; la determinación de la estructura social y la posición que ocupan las personas se verá reflejada en el lenguaje constituyéndose una comunicación que tiene como característica central la asimetría. Así, en la comunicación social circularían discursos que reflejan las representaciones sociales que las personas tienen, transmitiendo en ellos la ideología que sostienen estas posiciones asimétricas.

La ideología es un nivel de significación que puede estar presente en cualquier tipo de mensaje, desde los científicos hasta los cotidianos, formando el "horizonte de la realidad social en la que estamos viviendo", puesto que se constituye en un sistema de reglas semánticas para generar y decodificar 
mensajes. Siendo un concepto polisémico, tiene una función de integración social tendiente a la legitimación de las relaciones de poder. Son sistemas de valores y prácticas que demarcan posiciones sociales (Vila, 2001), refieren una posición de mundo que trata de imponerse en relaciones que reflejan permanentemente conflicto.

Una concepción ideologizada e ideologizante de la vida cotidiana impide ver y comprender las contradicciones y permite la aceptación como única forma posible de vivir. Particularmente para las personas que comparten condiciones de discriminación, como por ejemplo "las personas pobres" y los "jóvenes infractores". Los procesos de ideologización son muy importantes de analizar para entender la cultura que ellos conforman.

Ignacio Martín-Baró (1983) y Maritza Montero (2003) coinciden en plantear que la naturalización de ciertas ideas, valores y actitudes frente a la realidad, permite muchas veces la aceptación de lo inaceptable (como las injusticias sociales, la pobreza, la discriminación, entre otros). Sería a través de los mecanismos de habituación y familiarización que las situaciones anormales son percibidas como parte natural de la vida cotidiana (Montero, 1994).

Incluso Martín-Baró en su obra Acción e ideología (1983), plantea la relación entre orden social y estructura psicológica. El alude a una psicología de clase, refiriéndose con ello a ciertas formas de pensar, sentir y actuar que son propias de ciertas personas ubicadas en una determinada clase social en un momento histórico determinado. En las clases sociales que él señala como dominadas, se podría apreciar además del fatalismo, inmediatismo y desesperanza, el fenómeno de la alienación. En la alienación las personas asumirían como propios los valores e intereses sociales característicos de la clase social dominante. Este podría ser un referente para entender la inflación de expectativas de consumo que se aprecia en jóvenes infractores de ley ( $\mathrm{y}$ en otros sectores de la pobla- ción) las que justifican, por ejemplo, el robo como forma válida de acceder a lo que la "sociedad vitrina" ofrece.

Esto es un ejemplo palpable de que en el aprendizaje para constituirnos en sujetos sociales la matriz de relaciones socioculturales juega un rol fundamental. Pablo del Río (1996) agrega a esta idea que cada cultura genera fórmulas diversas de simbiosisidentitarias socioculturales, contando cada una de ellas con mecanismos culturales de mediación para hacer conciente y efectivo su nivel de identidad. A esta idea nos referiremos más adelante cuando abordemos el proceso de socialización.

\section{Cultura, Subcultura y Contracultura}

Para entender como se ubican las personas en la estructura social en función al grado de cercanía o lejanía de los valores y categorías definidas por la cultura mayor o cultura dominante pasaremos a continuación a definir lo que Vergara (1996) denomina cultura ideal, subculturas y contraculturas, ubicando el espacio en que se sitúan las personas que han sido definidas o que se definen como delincuentes.

La cultura ideal puede ser definida como las normas, valores, actitudes y percepciones necesarios para el mantenimiento de un orden social determinado, implicando una aceptación y legitimación de éste (Vergara, 1996). Constituiría un núcleo referencial e imaginario potenciado por la cultura dominante y en relación al cual se posicionan subculturas y contraculturas.

Las subculturas se posicionan más cercanas a la cultura ideal y constituirían una derivación del sistema cultural, la relación sería no conflictiva, pues los lazos no se rompen y la variante es sólo ramificación de la cultura global (Vergara, 1996). Entre las subculturas se pueden contemplar aquellas dadas por factores etáreos, religiosos, laborales, de clase social, étnicos y de género, entre otros. La es- 
tructura de las subculturas está compuesta por un núcleo subcultural determinado y fuerzas que atraen y repelen de éste. El núcleo lo componen normas, valores, actitudes y percepciones, jerarquizados y determinados por elementos identificatorios particulares (modos propios de hablar, vestir, etc.). La fuerza que atrae hacia el núcleo subcultural es el control social interno generado por el propio grupo; mientras que las fuerzas que alejan provienen de otras subculturas o contraculturas, así como desde la cultura dominante global.

La contracultura surge como reacción negativa al sistema cultural, primando una relación antagónica y conflictiva. Posee la misma estructura que las subculturas, pero a diferencias de éstas, suponen un núcleo contracultural mucho más definido con mucho mayor control social interno; generando mayor cohesión e identificación interna. Así, las contraculturas representan insuficiencias y fuertes contradicciones en la sociedad y deben entenderse como producto de la misma estructuración social y de ninguna forma como fenómenos aislados o generados de un modo autónomo (Vergara, 1996).

En este contexto, la delincuencia puede ser comprendida como una contracultura, caracterizada por la existencia de códigos éticos, lenguaje y estratificación característicos (Cooper, 1994), que cohesionan y otorgan identidad a quienes forman parte de ella.

En toda sociedad es de vital importancia la mantención del status quo, por lo que se busca situar a los grupos socioculturales en un plano de consenso social. La cultura dominante intentará mantener a las subculturas y contraculturas en un plano consensual, acercándolas a través de la persuasión y de la represión y buscando minimizar las diferencias culturales para homogenizarlas con la cultura ideal (Vergara, 1996).

Es así como, desde la perspectiva de la cultura dominante, la crisis o la desviación son definidas como eventos que dan cuenta de un "error" en el funcionamiento del sistema, el que debe ser corregido o controlado, permitiendo su reestabilización (Glauben y cols, 1993). En el caso de la delincuencia es fundamentalmente en el sistema jurídico dónde se buscará el ajuste.

En el ajuste y control social la familia cumple un rol básico consistente en formar a sus miembros nuevos para que desarrollen personalidades adaptadas, moral y productivamente, al sistema. Cuando las familias no logran esa adaptación se consideran "familias problemas" y el sistema social genera mecanismos reguladores que facilitan que cumpla con el rol esperado o reemplaza algunas de sus funciones. Así, la familia cumple con transmitir las representaciones sociales que facilitarán a hombres y mujeres relacionarse armónicamente con otras personas y otros sistemas sociales, dando continuidad a los roles históricos establecidos por la estructura de poder en la que viven.

Sin lugar a dudas las diferencias que se pueden apreciar en los distintos grupos sociales están marcadas por su pertenencia a determinada clase social. Pero esas diferencias como lo indica Pierre Bourdieu (1991) no sólo obedecen a diferencias en las relaciones económicas, por la propiedad de ciertos bienes o la carencia de ellos, sino que también responden a la forma de usar los bienes transformándolos en signos. Las prácticas culturales serían para este autor un conjunto de "características auxiliares" que a modo de exigencias tácitas pueden funcionar como principios de selección o de exclusión reales sin ser formalmente enunciadas o estipuladas. Allí se ubican los gustos, las prácticas cotidianas, las formas de vestir, entre muchas otras.

En esta perspectiva, la cultura ideal surge como un patrón de referencia que posibilita dar cuenta del grado de cercanía o alejamiento con respecto del mandato social predominante.

En cada estrato social, las subculturas y contraculturas complementan el sostén del 
orden social dominante. La delincuencia como contracultura, emerge en este marco como desviación indeseable que debe ser controlada de alguna forma para que el orden establecido mantenga su vigencia. Lo paradójico es que al mismo tiempo la delincuencia es producida y reproducida como efecto residual de las mismas relaciones de asimetría. Es decir, se la quiere exterminar o al menos controlar, pero el sistema vigente es impensable sin la desviación como elemento que justifique las instituciones de control social (Foucault, 1995)

En síntesis, podemos decir que la fragilidad de los vínculos sociales (mediados por un universo simbólico y por su ubicación en la estructura social), pueden dar origen al surgimiento de la desviación social. En este proceso hay una serie de factores psicosociales que entran en juego, pero por ahora destacaremos que necesariamente al existir una prescripción normativa se producirían procesos de desviación normativas en algunas personas o grupos que pueden llegar a constituir sus propias culturas, funcionalmente coherentes con la estructura social existente, aunque para ella signifiquen tensiones o conflictos.

\section{Representaciones Sociales y Construcción Social del Conocimiento}

En la actualidad, muchos investigadores comparten como idea que los seres humanos disponemos en la mente de lo que desde diferentes posiciones teóricas se denominan modelos mentales, representaciones, teorías implícitas, teorías ingenuas, sistemas de esquemas, etc. y que a partir de esos modelos realizamos las acciones e interpretamos la realidad (Delval, 1992).

Uno de los conceptos que mayor desarrollo ha tenido durante las tres últimas décadas es el de representaciones sociales, ofreciendo una alternativa teórica que ha impulsado la investigación empírica en psicología. Este concepto fue introducido por Serge Mocovici en la década del $60^{\prime}$ y ampliamente desarrollado por sus discípulos de allí en adelante.

Conceptualmente, representación social se refiere a la "actividad mental que despliegan los individuos y grupos con el fin de fijar su posición en relación con situaciones, acontecimientos, objetos y comunicaciones que les conciernen de la vida cotidiana y que se encuentran a la base de la construcción de una realidad social de orden consensual" (Jodelet, 1993: 473) son, además, para Moscovici y Hewstone (1993), teorías basadas en el sentido común y en esta función muestran cómo suceden las cosas. Dicho de otra forma, tienen por misión describir, clasificar y explicar; sin embargo, a diferencia del conocimiento generado a partir de la ciencia, las representaciones sociales rápidamente trasuntan explicaciones acerca de los eventos de la vida cotidiana, explicaciones fuertemente arraigadas al minuto de contactarse con la realidad social.

Según Moscovici (1988), las representaciones sociales tienden un puente entre el individuo, la cultura y la historia, es decir entre la subjetividad y la vida social de los individuos. Se relacionan, consecuentemente con los contenidos del pensamiento cotidiano, refiriéndose específicamente a las imágenes y modelos explicativos que un determinado grupo social tiene acerca de algún fenómeno de la realidad.

En lo que a función de las representaciones sociales respecta, ellas posibilitan a las personas orientarse y manejar su realidad material y social, facilitando, a su vez, que la comunicación tenga lugar entre los individuos. Ello ya que proveen a las personas de códigos para nombrar o clasificar los diferentes aspectos de su realidad personal y colectiva. Además, participan en la construcción de nuestra realidad dando sentido a los elementos que emanan de diversas fuentes (medios de comunicación masivos, conversación o encuentros con otras personas) que están en continuo movimiento social y cambio, transformando lo nuevo en habitual. 
Otras funciones específicas, atribuidas por Ibáñez (1988) a las representaciones, son que permiten que los sujetos integren nuevos elementos en el pensamiento social; generan formas para la toma de posición en situaciones sociales; colaboran en la aceptación de la realidad social instituida con la consecuente adecuación a la posición social correspondiente, $y$, finalmente, constituyen una de las bases para la conformación de la identidad social y de grupo.

Sin desconocer que las construcciones de la realidad social ocurren en un escenario social temporal e histórico y por tanto son influidas por el ambiente, diversos autores desde una perspectiva constructivista, resaltan el rol activo de los sujetos en esa construcción. De este modo, el conocimiento construido por el sujeto no es una copia de la realidad exterior sino que el producto de una elaboración personal, que puede ser facilitada por otros (Delval, 1992). La biología y la cultura cooperarían estrechamente en que esta construcción sea posible.

Para algunos autores, la actitud receptiva del medio social, que hace posible el proceso de socialización, existiría desde el nacimiento, mientras que para otros no habría una actitud social en el ser humano hasta que se convierte en interlocutor de otros seres humanos mediante el establecimiento de una alteridad, cuestión que no ocurre sino hasta avanzado el desarrollo infantil. Ambos acercamientos, sin embargo, concuerdan en señalar que es la familia, el sistema social más próximo y significativo para el niño (especialmente cuando pequeños), el encargado central de llevar a cabo el proceso de socialización, influyendo decididamente en como los individuos interpretan y se relacionan con la realidad social. La lógica propia del amor como fundamento de la construcción del sistema familiar, le proporciona un rol privilegiado en el moldeamiento de las conductas del niño y de su sentido de identidad
(Minuchin, 1982; Rodríguez, 1989). Ello porque el niño(a) siente condicionada la aceptación de los adultos significativos a la emisión de unas conductas por sobre otras.

La socialización, entonces, transmite al individuo estructuras de interpretación de la realidad social o modelos culturales, que se encuentran mediatizados por los otros significativos a cuyo cargo se hayan. Estas estructuras de interpretación son asimiladas progresivamente por el individuo, que luego contribuirá a reproducirlas. Esta internalización de estructuras de interpretación es, según Rodríguez (1989), la base para la comprensión del otro y del mundo, convirtiendo al sujeto en miembro de la sociedad.

De este modo, el mundo social aparece filtrado por otros significativos en función de la posición que ocupan en el mundo (clase social y cultura, entre otros) y sus biografías individuales. La internalización se completa cuando el sujeto es capaz de identificarse con los roles y actitudes de las personas más cercanas y adquiere una identidad propia subjetivamente coherente y plausible con el mundo social específico (Rodriguez, 1989).

\section{Proceso de Inadaptación Social: La Delincuencia en Contextos de Pobreza}

En la vida de cualquier sociedad, sobre todo en los núcleos poblacionales más grandes, es relativamente frecuente que aparezcan comportamientos contrarios a los valores y normas del sistema social. Estos comportamientos han sido conceptualizados de diversas formas, entre los que se cuentan el de desviación e inconformismo.

Es posible detectar notorias diferencias en la terminología empleada para designar a las personas que prescinden de las normas sociales o las quebrantan. En el lenguaje técnico, no es lo mismo hablar de delincuencia que de "desviación social"; de sociopatía que de "discordancia normativa". 
En este sentido, cabe distinguir dos perspectivas opuestas en la concepción del inconformismo normativo: una califica al inconforme como delincuente y la otra perspectiva lo califica como desviado o discrepante social (Valverde, 1996)

Desde la primera perspectiva, el quebrantamiento de las normas sociales constituye un fallo de orden moral y supone la alteración de las exigencias propias de cualquier vida humana en sociedad, por consiguiente, se trata de un acto "malo" en sí mismo. En la práctica, la comprensión y el alcance de la delincuencia se hacen desde la perspectiva de la ley. La ley se convierte así en intérprete del bien y del mal; de la normalidad y anormalidad; la responsabilidad de los actos delincuenciales, por su parte, reside únicamente en la persona, cualesquiera sean las causas que expliquen esos comportamientos o los factores que lo precipiten (Urra, 2000).

Para la segunda perspectiva, el quebramiento de las normas sociales consiste en el apartamiento del individuo respecto a las exigencias de su grupo. De por sí el acto desviado sólo indica una separación del orden estadístico, una divergencia respecto de lo que hace la mayoría. La comprensión de la desviación se hace desde la perspectiva de la estructura social, del sistema social imperante y de sus exigencias concretas. El quebramiento de las normas supone un acto disfuncional para el sistema en la medida que altera el comportamiento normal, lo que no quiere decir que la disfunción no tenga funcionalidad a otros niveles. Finalmente, la responsabilidad de la desviación no puede atribuirse sólo a la persona, sino que reside tanto en la persona como en el sistema social y en cada caso es necesario distinguir cuáles son los factores relevantes que dan razón a tal desviación.

La palabra delincuencia deriva del concepto jurídico de delito, que alude no a una conducta, sino a un acto concreto referido a figuras legales (Valverde, 1996); así, delin- cuente es quien comete un delito contemplado en un determinado código penal.

En el presente artículo, el enfoque adoptado no se restringe a la consideración judicial de lo delictivo, sino que busca relevar el proceso social, familiar e individual que lleva a un determinado individuo a manifestar de una manera más o menos permanente un tipo de comportamiento que incluye actos que el sistema social define como delitos. Se considerará la delincuencia como una forma más de inadaptación social, pero sin ser la única variable comportamental que define la interacción social de aquellos individuos que el sistema social define o etiqueta como delincuentes.

A nuestro entender la situación de desviación debe reconocerse como un proceso que evoluciona con el tiempo, con la historia del individuo y las características del entorno en donde se desarrolla. Para que exista desviación debieran presentarse los tres siguientes elementos (1) existencia de una norma, (2) un comportamiento de trasgresión de la norma y (3) un proceso de estigmatización de la conducta.

De acuerdo a nuestra experiencia en terreno, el tercer aspecto referido es de crucial relevancia. Este proceso de etiquetación y estigmatización durante el desarrollo de ciertos niños y jóvenes va marcando (en conjunto con otros sucesos) una construcción de identidad específica como trasgresor de normas. En ello intervienen, desde la familia hasta las instituciones de educación y control social, pero también la opinión pública y los medios de comunicación de masas. Estas instancias, muy tempranamente en función de prejuicios y expectativas, van demarcando que cierto tipo de personas sean desviados sociales.

Por otra parte, una serie de autores indican como factor relevante en la conducta delictiva y su reincidencia, el desarrollo socioeconómico, la pobreza y la inequidad distributiva (Arias, 1995; Zambrano, 2001 y Moreno, 2001). De este modo, la delincuen- 
cia se mostraría mayoritariamente en las grandes ciudades teniendo como principal determinante la acumulación desmedida de riqueza por pequeños sectores, en detrimento de una amplia población que se ubica en sectores urbanos marginales o populares. En esta perspectiva, Cooper (1994) indica que en Chile los problemas sociales de la extrema pobreza y la pobreza se asocian a la delincuencia común, en un $90 \%$ y en un $8 \%$ de los casos, respectivamente.

Se constata, además, que quienes están más expuestos a ser detenidos y recluidos en centros de control social, son los pobres. Así, no sólo tienen mayor probabilidad de transgredir la norma establecida, sino que también están más expuestos a ser castigados por el sistema social. Como lo destaca claramente Michel Foucault (1995) el poder se hace presente para elegir las formas de castigo para los que son entendidos como "anormales", para seleccionar a quienes serán rotulados como desviados y a los agentes sociales que operarán en el castigo o rehabilitación.

Queremos destacar aquí que el fenómeno de la delincuencia se encuentra fuertemente asociado a las condiciones de pobre$\mathrm{za}$, pues en ella se ven limitados los recursos que permiten integrarse "apropiadamente" al orden social dominante (Pérez-Luco y Alarcón, 1992). Lejos de indicar una explicación monocausal de la delincuencia, lo que se busca es enfatizar que un medio social desventajoso reúne condiciones que predisponen a quienes en ese medio se desarrollan, a desarrollar conductas antisociales en la medida que disponen de menos y más débiles recursos protectores (familia, inserción institucional, información) frente a riesgos mayores (la calle, violencia, carencias materiales y afectivas).

La pobreza de acuerdo a Pérez-Luco (1994) es la resultante de un orden social excluyente revelado en una condición de vida que impregna de carencia y frustración todas las esferas de la experiencia humana, transmitiéndose transgeneracionalmente a través de pautas culturales y mandatos familiares que actúan como freno al potencial de desarrollo individual, familiar y social. La pobreza como un fenómeno complejo, constituye un sistema de relaciones sociales, culturales y económicas con un componente estructural a dos bandos: uno objetivo-material, ligado a la carencia de oportunidades y condiciones básicas de vida y otro subjetivorelacional que determina particulares formas de interpretar la realidad y de relacionarse, como mecanismos de adaptación a circunstancias adversas (Zambrano, 2003). La pobreza, es así, un obstáculo central para el desarrollo de las personas en la medida que transgrede sus derechos más básicos impidiendo el desarrollo pleno de potencialidades.

Por ello, muchas familias en condiciones de pobreza, deben acudir a una diversidad de arreglos estructurales y funcionales que le permiten adaptarse a un sistema que, en términos generales, sobrepasa su dominio. De este modo, se desenvuelve desarrollando características propias, definidas por la exclusión de muchas oportunidades de desarrollo, que le hacen adoptar diversas estrategias o "arreglos" para lograr la subsistencia y adaptación a la cultura dominante (Espinoza, 1993). Estas formas de funcionamiento y estructura suelen transmitirse mediante socialización a las siguientes generaciones.

Las dificultades de subsistencia material afectan casi inevitablemente el desarrollo personal de sus miembros, por cuanto dichas carencias van modificando la estructura familiar y generando un ambiente de inseguridad y abandono que dificulta la convivencia e impide a los adultos crear un espacio de socialización que satisfaga las necesidades del niño (Rodríguez, 1989). Esto se aprecia en cambios de pareja que exponen a los hijos a figuras parentales itinerantes que imponen (o se acomodan a) estilos de relación distintos y con los cuales no existe un vínculo definido en relación a la autoridad, las normas o el afecto. 


\section{Surgimiento de problemas psicosociales en contextos de vida precarios}

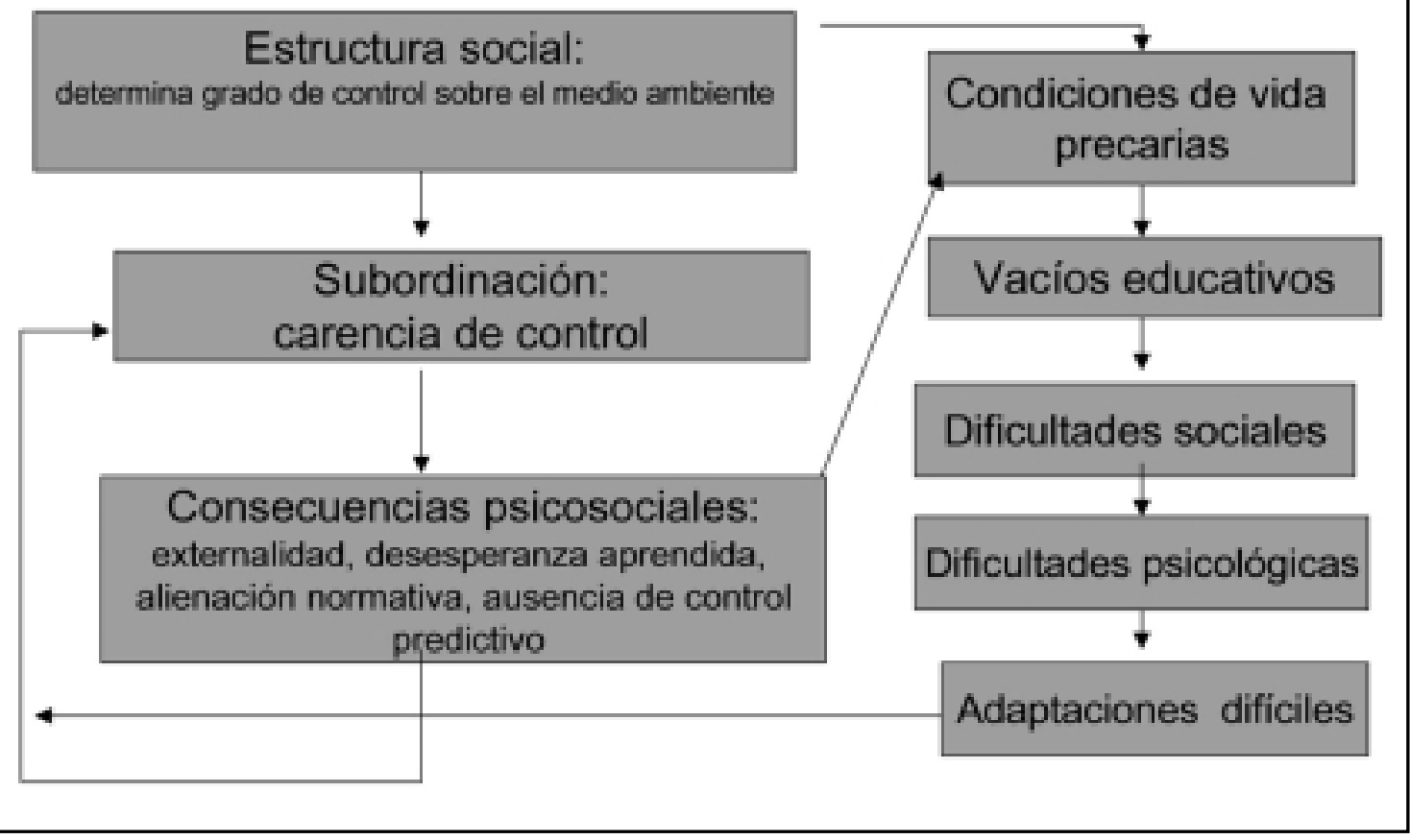

El esquema resalta que algunas familias ubicadas en estratos socioeconómicos bajos, dadas sus condiciones de subordinación frente al resto de la sociedad no tienen acceso a oportunidades ni pueden, en la mayor parte de las ocasiones, desarrollar competencias, habilidades o conocimientos para acceder a ellas por presentar grandes vacíos educativos. Estos últimos tienen implicancias en la construcción de identidad ya que el niño al tener dificultades para presentar las conductas esperadas para su edad y para interactuar apropiadamente con los otros experimentará la tensión de no responder a las expectativas sociales.

La dificultad para ejercer control en cuestiones tan vitales como satisfacer necesidades básicas para la subsistencia, generan consecuencias como la sensación de que los eventos de la vida son definidos y resueltos por otros, perdiéndose la fe en que las condiciones actuales o futuras puedan ser mo- dificadas por la propia acción y disminuyendo la motivación para intentar mejorarlas. Esta falta de poder objetivo de las personas sobre su situación vital se perpetúa en la medida que los individuos se paralizan y sólo se movilizan en torno a la sobrevivencia del día a día (Zambrano, 2001).

Las condiciones de vida precarias, en lo material y/o afectivo, imposibilitan a los niños que allí se desarrollan el aprender oportunamente normas, formas de relación afectiva, habilidades y competencias que permitan una adecuada integración a la vida social, donde la noción de "adecuación" hace referencia a los estándares sociales establecidos como deseables para la convivencia social. Todo esto redunda a nivel psicológico en una baja autoestima, sentimientos de frustración y el surgimiento de mecanismos psicológicos compensatorios de las dificultades experimentadas en la relación con los otros. 
Así, las relaciones afectivas establecidas al interior de las familias tienden a seguir un diseño preestablecido en las biografías de los propios padres. La relación que se da entre los niños y los adultos resulta, con frecuencia, poco empática, acentuando su asimetría y favoreciendo en los niños el desarrollo de sentimientos de infravaloración y permutabilidad. La individualidad del niño no suele ser considerada, las cosas no le pertenecen y debe someterse a las altas exigencias impuestas por los adultos. Los padres y el entorno, van constituyendo entonces para los niños, en general, imágenes amenazantes que pasan a formar parte de su mundo interno.

Los niños, se van transformando en "niños adultos", que tienen que hacerse cargo de una rápida acomodación a la realidad a la que pertenecen, pues quienes son responsables de su cuidado también tienen múltiples carencias provenientes de su propia infancia, las que provocan una sobrecarga psíquica que en muchas ocasiones dificulta hacerse cargo de otro (Pérez-Luco y Alarcón, 1992). Como no logran relacionarse afectivamente con sus propios hijos, es frecuente observar serios trastornos del vínculo afectivo entre ambas partes (Rubio, 1985; Rodríguez, 1989; Barudy, 2001). En esta perspectiva, se puede sostener que la pobreza material se transforma en vivencias, relaciones y experiencias tempranas de carencia que van estructurando en las personas que crecen allí, una particular dinámica psíquica. Este es un proceso que se inicia en la niñez temprana y que continúa en las siguientes etapas evolutivas.

\section{Delincuencia Juvenil: Una Mirada desde la Construcción de Identidad}

La literatura de actualidad señala que las ideas que tienen los individuos acerca de sí mismo y de su medio social, aspectos centrales de la construcción de identidad, determinan en gran medida su conducta social.

La identidad social es aprendida a través de un sistema de representaciones relativa- mente intuitivas que oponen rasgos negativos a positivos propuestos por el grupo como modelo ideal. Constituye, además un sistema socialmente establecido y se expresa en un discurso que implica un sistema de ideas relativamente coherentes y que responde a una ideología (Montero, 1987). Es así, que delimitar el tipo de representaciones sociales que subyacen a la construcción de la identidad delictiva permitiría comprender aquellos aspectos simbólicos que conectan y ubican como delincuente a un individuo en el espacio personal y social.

Proponemos que las representaciones sociales que construyen los miembros de una familia, se asocian con el estilo de afrontamiento que ellas tienen ante la realidad y viceversa. Ello porque, como lo hemos señalado, son las familias en donde fundamentalmente se construye la subjetividad o ideología, en la medida que ellas, a través del lenguaje, establecen un orden simbólico que reproduce el sistema social, cultural, económico y político dominante (Glauben y Cols., 1993).

Puesto que la vida se les presenta a las personas como un verdadero caos, requieren formarse una interpretación de sí y del mundo que les garantice un cierto "orden" y certidumbre. La representación de un "orden" permite que la persona afirme su identidad individual como también su identidad colectiva en su dimensión de clase social, género, minoría, mayoría, etc. Esto supone demarcar roles, territorio, rivales, aliados y poner en juego la dimensión simbólica, institucional y política (Gutierrez-Castañeda, 1994, citado en R. Vila 2001).

La teoría de la identidad social propuesta por Tajfel y Turner (1979), resalta la pertenencia al grupo en la definición de sí mismo, pero considera la dinámica identitaria en términos personales, planteando un continuum en que los individuos serían tratados como una singularidad y especificidad individual al mismo tiempo que, en el otro polo, son tratados como un sujeto que pertenece a un determinado grupo social (Bourkis y Leyens, 1996). 
Identidad es en términos simples, la imagen y el concepto que tenemos de nosotros mismos. Cada persona tiene una imagen consciente o inconsciente de sí mismo que se construye y forma a lo largo de la propia historia vital, pero obviamente no es un proceso en solitario, es una tarea que se efectúa junto con otros, como la familia, los pares, la comunidad. Sostenemos que la construcción de identidad es un proceso ecológico en la medida que se desarrolla en interacción con diversos espacios y entidades, añadiendo además, que la vivencia de ser uno mismo y el sentimiento de pertenencia a un grupo, como la familia, ayudan a mantener la seguridad emocional y la capacidad de acción en coherencia con aquellos valores y normas asumidas como propias (Beristain y Rivera, 1992).

Amin Maalouf (2002) resalta el peligro de favorecer y obligar a las personas a adscribirse a una identidad fija y absoluta, señalando que la identidad está formada por una infinidad de elementos que se corresponden a nuestras múltiples pertenencias sociales (familia, nación, religión, etnia, pandilla, grupo de amigos, entre otros). Estas pertenencias no tienen la misma importancia en un mismo momento (pueden variar según las circunstancias), pero ninguna de ellas carece totalmente de valor. Agrega además que aunque muchas personas compartan un gran número de elementos, nunca se da la misma combinación en dos personas distintas, lo que hace que cada persona sea singular.

Si bien la identidad desde esta perspectiva, es una construcción continua, no fija, está mediada por los roles sociales, cumpliendo una función particular en el orden social. De este modo, las personas, se ven interpeladas a fijar su identidad de un modo rígido cumpliendo roles que les impiden desarrollar todo su potencial y riqueza. Este es el caso concreto de los jóvenes que presentan problemas de "adaptación social".

Así, el desarrollo de la identidad personal y familiar permiten que sea posible la relación de la persona con los distintos ámbitos de la sociedad y las representaciones sociales (como mecanismo intermedio) en su dimensiones cognitiva, afectiva y actitudinal, permite a las personas responder a las preguntas básicas que se plantean en el proceso de construcción de identidad psicosocial.

Para poder comprender el proceso de construcción de identidad en jóvenes infractores de ley, debemos considerar que la primera etapa de socialización ocurre en un marco de inestabilidad que se proyecta en los diversos ámbitos que rodean la vida familiar. En este contexto los niños y jóvenes se ubican como espectadores de lo que ocurre a su alrededor, experimentando vivencias de "marginación", "abandono", "desprotección" y "condicionalidad afectiva" que pasan a formar parte central de su construcción de identidad (Alarcón, PérezLuco y Lucero 1992; Zambrano 2001).

Se produce como lo ha indicado Barudy (2001) un proceso de victimización temprana, en donde el niño no puede resolver sus necesidades, transformándose en muchas ocasiones en "objeto" para resolver necesidades o dificultades de los adultos, tales como situaciones de maltrato, abuso o negligencia. Estas relaciones tempranas, que comunican de algún modo al niño su permutabilidad y falta de valor, tamiza la construcción que de sí mismo realiza, acudiendo a formas de relación que reproducen, en la mayor parte de las ocasiones, los esquemas incorporados tempranamente. De este modo, la identidad se construye sobre la desconfianza, la inestabilidad de las relaciones, infravaloración de sí mismo, agresividad y pasividad como parte de las "opciones" que adopta para enfrentarse a una realidad que las más de las veces percibe como amenazadora.

En un contexto que no ofrece las oportunidades para desarrollar recursos, aprendizajes y habilidades compatibles con los requerimientos sociales y que por el contrario obliga a desplegar toda la creatividad en la sobrevivencia, las posibilidades de transgredir la norma son mayores. 
La preadolescencia y adolescencia son un período evolutivo que asume características especiales para los jóvenes que se desarrollan en contexto de carencia. La coexistencia de cambios físicos y psicológicos adicionados a las presiones ambientales, los hacen susceptibles de vivir con especial incertidumbre el período.

La convivencia cercana con grupos con compromiso delictivo, sumado a una familia que no es capaz de orientar y disciplinar, inciden en que el joven termine viviendo en un sistema organizado de tal manera que el "medio exterior" cercano no afecta sus premisas que justifican que se conduzca como violador de reglas (Fischman, 1989). Como consecuencia de esto, el joven va construyendo una representación de sí mismo basado en sus competencias delictivas y su capacidad para transgredir eficientemente la norma. Tiene dificultades, por tanto, para conectarse con un contexto más funcional que saque a la luz sus habilidades y recursos no delictivos.

De tal modo, la secuencia de conductas, del niño y adolescente que aparece como inadaptado a los ojos de un observador externo, resultan ser un intento permanente de adaptación a las distintas situaciones vitales y es la anormalidad de esas situaciones la que determina la anormalidad de su comportamiento.

Valverde, en su obra "El proceso de inadaptación social", define al inadaptado como una persona tan adaptada que se inadapta para poder adaptarse, pero las circunstancias de su vida y las escasas habilidades sociales que ha podido desarrollar no permiten que sea una adaptación eficaz -al menos mirado desde el medio social normalizado- sobre todo cuando las instituciones de control social enjuician conductas concretas (Valverde, 1996).

Estas conductas desadaptadas provocan inevitablemente la intervención de las instituciones de control social, no sobre el entorno, como sería necesario, sino sobre el individuo particular. En la medida que el muchacho va experimentando las presiones de las exigencias institucionales o recoge en la interacción con el personal que allí labora una imagen estigmatizada y devaluada de sí mismo, se produce una progresiva personalización del conflicto. Esto lo conduce a considerarse a sí mismo inadaptado (o delincuente) $\mathrm{y}$, asumiendo esa etiqueta, tenderá a alejarse progresivamente de las normas convencionales de conducta y desarrollará pautas de comportamientos en consonancia con la dinámica conflictiva en que se ve envuelto. En consecuencia, la formalización del inadaptado como delincuente se produce a propósito de la reacción social e institucional brindada como respuesta jurídica a problemas que, como hemos examinado, son de otra naturaleza.

Como lo describe Goffman (1998: 48), bajo el concepto de carrera moral, parte de este proceso de socialización secundaria consiste en que "la persona estigmatizada aprende a incorporar el punto de vista de los normales, adquiriendo así creencias relativas a la identidad de lo que significa poseer un estigma particular".

Estas circunstancias promueven un fuerte proceso de identificación con los pares, en donde se experimenta cierta libertad e incondicionalidad, obviamente relativa. Así, el rol que pasan a cumplir los grupos (pandillas, por ejemplo) se potencia en la medida que se constituye en una instancia de referencia, pertenencia, afecto e identificación, lo que favorece el acercamiento de los jóvenes a pautas de funcionamiento de carácter delictivo.

Es en la llamada "carrera delictiva", en la que se ven implicados algunos preadolescentes y adolescentes, donde comienza a producirse la definición de sí mismo en base a valores y prácticas propias del mundo delictivo. Es en el continuo ir y venir entre las instituciones de protección, rehabilitación, control social y el medio en el cual se mueve normalmente con su grupo de pares donde va aumentando el compromiso delictual (Zambrano, 2001). Con todo, es gracias a esta identidad que los jóvenes pueden sentirse "parte de" una cultura propia, en contraposición a la vivencia de sentirse "demás" en el resto de la sociedad. 


\section{Propuestas, Comentarios Finales}

Hemos planteado que la infracción de ley configurada en un patrón de conducta recurrente, en el caso de un número importante de jóvenes, es la resultante de un proceso que tiene fuertes vinculaciones con un medio social desventajoso, que genera inseguridad, estrés, desesperanza y dificultades para resolver necesidades básicas materiales y psicológicas. A menudo también, se relaciona con problemas estructurales y funcionales de la familia, los que aportan en la construcción de un paradigma familiar que se representa a sí misma y al resto de la realidad de un modo particular, redundando finalmente en un estilo diferenciado de afrontamiento eventos y relaciones interpersonales cotidianas. Estos patrones de interacción con la realidad son adaptativos en el contexto en que se dan y resultan ser verdaderos mandatos familiares enraizados en las representaciones sociales que los distintos integrantes de la familia construyen acerca de sí mismos y su mundo. La recurrencia y carácter compartido de estas representaciones sociales otorgarían identidad al joven y a su grupo familiar.

En el contexto descrito, entenderemos por identidad delictiva al sentido de sí mismo (experiencias, sentimientos, capacidades, motivaciones y anhelos), ante sí y ante los ojos de los demás, que se ha conformado en base a pautas de valoración distanciadas del orden social establecido en la cultura global, pero fuertemente arraigadas y compartidas con un grupo social de referencia que valida y promueve papeles, reglas y representaciones sociales dentro de una contracultura delictual.

Podríamos señalar que al no operar el cuestionamiento sobre las representaciones sociales que se expresan en la comunicación de la vida cotidiana, las actitudes y conductas se hacen recurrentes y consistentes con esas representaciones. Entonces, para pensar en el cambio, es imprescindible que las personas recreen representaciones sociales distintas a las que han logrado configurar durante su vida.
Esto sería posible a partir del cuestionamiento, conflicto y desafío de las representaciones sociales del mundo. Este cuestionamiento se hace viable cuando el sujeto logra interactuar en ámbitos diversos que amplían y enriquecen sus experiencias. Un sujeto que se desenvuelve en un campo o contexto reducido tenderá inevitablemente a reforzar sus representaciones con "más de lo mismo", confirmándolas y fortaleciéndolas de tal modo que aparecen como una realidad que no amerita ningún reparo. Las instituciones de control social, especialmente la prisión, adquieren un rol reproductor de la delincuencia en la medida que se transforma en una suerte de sistema cerrado, al que se "acopla" el mundo del hampa que entra y sale de ella, reproduciendo afuera los valores y normas que allí se recrean.

De acuerdo, a lo propuesto por Glauben y Cols. (1993), las personas al ampliar sus dominios cognitivos o representacionales, lo que en principio se expresa en la ampliación de su lenguaje (pauta lingüística), desarrollan mayor autonomía en la elaboración de distintas respuestas en su vivir cotidiano.

Lo mismo ocurre si a propósito de la ampliación del repertorio conductual se provoca una reinterpretación que permita al joven con compromiso delictivo (acompañado de otras estrategias) cuestionar y en ocasiones alejarse de las premisas del sí mismo como "violador de norma" o "malo" y desarrollar competencias distintas a la de "ladrón eficiente" o "trasgresor permanente". De esta forma se cuestionarían las representaciones sociales que le dan coherencia a esa identidad delictiva básica.

Este proceso, obviamente es lento y no exento de frustraciones y debiera estar mediado por un terapeuta o educador capaz de establecer un lazo afectivo estable y significativo, que también desafíe las experiencias de inestabilidad, de pérdida y de desconfian$\mathrm{za}$, revitalizando en el joven el valor de comprometerse afectivamente. Esto debiera acompañarse paralelamente de una habilita- 
ción escolar funcional y de una formación psicosocial y técnica que los prepare para una inserción laboral viable.

Estas tareas pasan por revalorizar el cotidiano, lo insignificante, lo que se vive irreflexivamente por ser "lo natural". Desde una concepción psicoeducativa se trata de que el adulto (operador social) pueda propiciar una "alteridad reflexiva" entre los muchachos, entre él y los jóvenes, en donde se puedan ver reflejados con confianza, y donde pueden surgir contradicciones y nuevas preguntas. Sabemos que la actividad reflexiva a la que aludimos requiere de ciertos recursos que los muchachos y los propios educadores a veces no han podido actualizar, ello llama a poner atención en el entrenamiento de habilidades de estos últimos para actuar de dinamizadores de este proceso.

Una propuesta más cercana a la prevención debiera necesariamente fortalecer a los grupos familiares, especialmente en los ámbitos en que presentan menor experiencia, conocimiento o efectividad, particularmente aquellos que hemos referido como factores de riesgo para el desarrollo de niños que se acercan a la desviación social. En el convencimiento de que los padres actúan como actúan porque no conocen otra forma de hacerlo, un proceso de formación en pautas de crianza, comunicación, afectividad, resolución de conflictos, es fundamental. Estos son mecanismos que pueden aportar a los padres u otros referentes adultos a sentirse más competentes en su relación con el niño o joven. Recordemos que la escalada de intervenciones sobre las familias que han sido definidas como "problema" colabora en la estructuración de un sentido de ineficacia que paraliza a los adultos o les hace mantener patrones cada vez más rígidos y violentos para ejercer control.

En el ámbito educacional, los profesores debieran conocer la realidad de estos niños no ya desde sus representaciones del lado "normal de la sociedad", sino desde un acercamiento mucho más comprensivo. El desafío es que establezcan, más allá de la relación orientada a la tarea académica, una relación de proximidad afectiva, relativizando sus propios valores y normas para acercarse a la percepción que el niño tiene como fruto de su propia biografía y pertenencia cultural. Sólo desde esta comprensión básica y desde la aceptación, se puede tener posibilidades de aportar para que el niño se mantenga significativamente relacionado con la escuela, disminuyendo, al menos parcialmente, el atractivo de "la calle".

Nuestra convicción es que se requiere de intervenciones de corte comunitario, de promoción y dinamización en distintos niveles, que aún cuando combine estrategias de mayor especialización sea inespecífica en el sentido de no focalizarse exclusivamente en la población que se ha definido como de riesgo. Hacerlo fomenta los componentes de discriminación y estigmatización. Estrategias integrales, con asiento territorial, flexibles y multinivel pueden evitar el riesgo de la discriminación y estigmatización que fomentan identitidades rígidas.

Todas estas propuestas preliminares carecerían de sentido si dejamos de reconocer y actuar en la dimensión estructural de la sociedad. Es necesario revelarse ante la injusticia, frente a la existencia de la pobreza, ante las respuestas mediáticas de tipo asistencialista (que no hacen otra cosa que reafirmar el fatalismo, dependencia y externalidad psicológica), rechazar las ideologías que sustentan la negación de la persona del "delincuente". Mientras la ética predominante no sea el pleno respeto de los derechos humanos y el compromiso con el cambio social subversivo (el que rompe la naturalización de las ideologías que favorecen la dominación), la delincuencia tendrá un espacio privilegiado para su desarrollo.

La Psicología y otras disciplinas deben recuperar su capacidad de crítica y propuesta frente a fenómenos sociales que impiden el desarrollo humano, eso significa necesariamente transformarse en sujetos políticos. 


\section{Referencias}

Aguirre, A. (2000). Demarcación de la Psicología Cultural. Anuario de Psicología Vol.32, $\mathrm{N}^{\mathrm{o}} 4$. Universidad de Barcelona.

Alarcón, P.; Pérez-Luco, R. y Lucero, C. (1992). Perfil emocional de los niños que delinquen como estrategia de adaptación: una comprensión clínico-social como propuesta de trabajo. Temuco: Revista Frontera $\mathrm{N}^{\mathrm{o}} 11$ (9-18).

Ávalos, S. (1990). Los menores infractores. Niños de la calle. Santiago: UNICEF-Hogar de Cristo.

BARUDY, J. (2001). Maltrato infantil. Santiago: Editorial Galdoc.

Beristain, C. y Rivera, F. (1992). Salud mental: la comunidad como apoyo. San Salvador: Virus Editorial.

BERGER, P. y LuCKMANN, T. (1968). La construcción social de la realidad. Buenos Aires: Amorrortu.

Bourdieu, P. (1991). El sentido práctico. Cap. 8, Los modos de dominación. Madrid: Taurus Ediciones.

BOURKIS, R. y LEYENS, J. (1996). Estereotipos, discriminación y relaciones entre grupos. Madrid: Mc Graw-Hill.

Cooper, D. (1994). Delincuencia común en Chile. Santiago: LOM Ediciones.

Del Río, P. (1996). Algunas promesas y limitaciones de la perspectiva sociocultural. Psicología explicativa y psicología implicativa. En D. Páez (ED.) La teoría sociocultural y psicología social actual. Madrid: Cultura y Conciencia.

Delval, J. (1992). El constructivismo y la adquisición del conocimiento social. Apuntes de Psicología. No 36, 5-24, Revista del Colegio Oficial de Psicólogos de Andalucía Occidental.
Egenau, P. y Nicholls, E. (1990). Juventud, delincuencia y prisionización. En Generación (Comp.) Los jóvenes en Chile hoy: Santiago: Cide-Cieplan-Inchi-Psi-Sur.

EspinOZA, J. (1993). Hacia un concepto de familia. Santiago: Proefa.

Fernández, P. (1994). Psicología Social, Intersubjetividad y Psicología Colectiva. En M. Montero (Comp.) Psicología Social Comunitaria. México: Universidad de Guadalajara.

Fischman, CH. (1989). Tratamiento de adolescentes con problemas. Capítulo III: Tratamiento de la delincuencia: Abordar las premisas del sí mismo. Buenos Aires: Paidós.

FouCAuLt, M. (1995). Un diálogo sobre el poder. Madrid: Alianza Editorial.

FuENZALIDA, I. (1996). El medio social desventajoso y la conducta socialmente desviada. Revista Chilena de Ciencia Penitenciaria $y$ de Derecho Penal. № 22, (13-19).

Glauben, L.; Panchana, P.; Pantoja, J.; Ramirez, M. y Rodríguez, C. (1993). Familia y comunidad un aporte a la noción del cambio en el campo de la acción social. Santiago: Proefa.

Goffman, E. (1998). Estigma. La identidad deteriorada. Buenos Aires: Amorrortu.

IвAÑEz, T. (1988). Ideologías de la vida cotidiana. Barcelona: Sendai Ediciones.

KLIKSBERG, B. (2001). El crecimiento de la criminalidad en América Latina: un tema urgente. Magazine DHIAL, Ed. N 29.

Llanos, M. y Sinclair, A. (1991). La familia del menor infractor de ley. Revista chilena de ciencia penitenciaria y derecho penal. $\mathrm{N}^{\mathrm{o}}$ $16(123-129)$

MaAlouf, A. (2002). Identidades asesinas. Madrid: Alianza Editorial. 
Minuchin, S. (1982). Familias y terapia familiar. Buenos Aires: Gedisa.

MARTín-BARÓ, I. (1983). Acción e ideología: Psicología social desde Centro América I. San Salvador: UCA Editores.

Martín-BARó, I. (1989). Sistema, Grupo y Poder. Psicología social desde Centro América II. San Salvador: UCA Editores.

Moreno, M. (2001). Psicología de la marginación social. Concepto, ámbito y actuaciones. Málaga: Ediciones Aljibe.

Montero, M. (1994). Proceso de influencia social consciente e inconsciente en el trabajo psicosocial. En M. Montero (Comp.) Psicología Social Comunitaria. México: Universidad de Guadalajara.

Montero, M. (2003). Teoría y práctica de la Psicología Comunitaria. La tensión entre comunidad y sociedad. Buenos Aires: Paidós.

Moscovici, S. (1988). Notes towards a description of social representations. European journal of social psychology. 18, (211-250).

Moscovici, S. y Hewstone, M. (1993) De la ciencia al sentido común. Psicología social II pensamiento, vida social y problemas sociales. Barcelona: Paidós.

Pérez-Luco, R. (1994). Pobreza en América Latina: significados y abordajes. Pasos hacia una visión ecosistémica. Tesis de Maestría. México: FLACSO

Pérez-Luco, R. y Alarcón, P. (1992). Impactos psicosocial de la condición de opresión permanente en los sectores marginales. Temuco: Revista Frontera No 11 (55-60)

Rodríguez, C. (1989). Cicatrices de la pobreza. Un estudio psicoanalitico. Caracas: Nueva Sociedad.

Rodríguez, D. y ARnOld, M. (1991). Sociedad y teoría de sistemas. Santiago: Editorial Universitaria.
Rubio, V. (1985). Estudio de carencias afectivas y la posible influencia negativa futura. Madrid: Dirección General de Protección Jurídica del Menor, Ministerio de Justicia.

Tafjel, H. y Turner, J. C. (1979). An integrative theory of intergroup conflict. In W.G. Austin y S. Worchel (Eds.). The social psychology of intergroup relation. Belmos, CA: Wadsworth.

ThOMPSON, J. (1998). Ideología y cultura moderna. México: Universidad Autónoma Metropolitana.

Urra, J. (2000). Adolescentes en conflicto. 29 casos reales. Madrid: Pirámide.

VAlverde, J. (1996). Proceso de inadaptación social. Madrid: Editorial Popular S.A.

VILA, R. (2001). Las identidades colectivas entre la construcción y la deconstrucción. Revista Acta Académica Universidad Autónoma de Centro América.

VERGARA, R. (1996). Ladrones y sociedad: análisis cultural de su dinámica. Revista chilena de ciencia Penitenciaria y derecho penal. $\mathrm{N}^{\mathrm{o}} 22$.

VAlsiner, J. y VAn Der Veer, R. (1996). Desde el gesto hasta el self: perspectivas comunes en las sociopsicologías de George Mead y Lev Vygotski. La teoría sociocultural y la psicología social actual. Colección Cultura y Conciencia

ZAMBrano, A. (2001). Pobreza, marginalidad y desviación: el rol mediador de la identidad familiar. En R. Pérez-Luco (Comp.). De la mano de los niños: nuevas miradas para construir nuevos caminos. UFROSENAME.

Zambrano, A.; Ballestros, R. y Galindo, C. (2001) La resiliencia como metáfora de una nueva mirada en la intervención psicosocial. En R. Pérez-Luco (Comp.). De la mano de los niños: nuevas miradas para construir nuevos caminos. UFROSENAME. 
ZAMBRANO, A. (2004). Liderazgo y valores para el empoderamiento en el espacio local y regional. Desarrollo endógeno en la Frontera. En P. Vergara y H. Von Baer (Eds.) Temuco. IDER (UFRO)-Fundación Ford. 